\title{
CARDIOVASCULAR CHANGES FOLLOWING ELECTRO-CONVULSIVE THERAPY
}

\author{
BY \\ RALPH KAUNTZE AND GERALD PARSONS-SMITH
}

\author{
From St. George's Hospital
}

Received January 7, 1948

Electro-convulsive therapy was first used extensively in 1939, and with such success that three years later Kolb and Vogel (1942) in a survey of the United States reported its use in 42 per cent of mental hospitals and in the treatment of 2.3 per cent of all mental hospital patients; this latter group was comprised of the schizophrenias, the manic-depressive states, involutional melancholias, and the psychoneuroses. As convulsant treatment is now of established value in the affective neuroses and as electric shock has largely superseded insulin and metrazol as a convulsant, it seemed pertinent to attempt some assessment both clinically and electrocardiographically of its effect on the cardiovascular system. These observations consisted of a clinical history (which by the nature of the psychiatric condition was not always complete), a routine examination of the cardiovascular system and electrocardiograms .(standard leads only) both before and after the convulsion. The second cardiogram was taken in the recovery phase directly after the clonic movements had ceased; in some instances there was slight delay due to uncontrollable spasmodic movements. The patients in this series were not specially selected; a quarter were observed during their initial treatments.

The convulsant apparatus used was that of Strauss and MacPhail (1946), which by means of a rapidly discharging condenser yields the higher voltages at the start, thereby overcoming the initial resistance, and as only minimal energy is then necessary to induce the fit, the equally rapid damping minimizes subsequent neuronic bombardment. The time factor is therefore of less importance and the dosage is reckoned in Joules or total energy rather than in in volts: this varies according to weight and general fragility; the usual dosage in this series was 18 Joules diphasic. A monophasic discharge yields a quieter recovery but is less certain in inducing a convulsion. The electrodes, soaked in 20 per cent saline, are applied to the temples, anterior to and a little above the external auditory meati. The duration of the shock is' variable, lasting about 0.35 sec.; unconsciousness is instantaneous and is succeeded by a tonic phase, thence a clonic phase, which in turn is followed by exhaustion and relaxation or irritability, from which consciousness is recovered in from four to fifteen minutes-a consciousness clouded by disorientation and amnesia. Occasionally the shock may produce a "stun" only, the patient remaining conscious. Successive "stuns" may induce cardiovascular collapse. The average duration of the tonic phase, as observed in 22 patients, was 16 seconds, of the clonic phase 25 seconds. The length of the tonic period bore no relationship to that of the clonic. Directly after the shock oxygen was administered by mask, and as the tonic phase is short, cyanosis was not observed.

\section{RESULTS}

Fifty-one patients, of whom 38 were women and 13 men, were observed before and after 63 electroconvulsions. The presenting psychiatric symptom in 82 per cent was depression. The average findings in pulse rates and blood pressures are set out in Table I. In seven instances the pulse rate following the convulsion remained unchanged or was decreased; in the main there was considerable increase.

The systolic blood pressure following the convulsion was elevated in about a third, showed no significant change (systolic $\pm 10 \mathrm{~mm}$., diastolic \pm 5 $\mathrm{mm}$.) in a third and was actually lowered in the remainder. Where an increase occurred, this lay usually between 20 and $35 \mathrm{~mm}$. and was accompanied in under a third, by a small fall in the diastolic reading. The maximum increase was $55 \mathrm{~mm}$., from $135 / 70$ to $190 / 95$ in a man, aged 27 , who displayed marked restlessness and considerable tachycardia. However, restlessness with tachycardia was not invariably accompanied by a rise in the blood pressure. 
TABLE I

Pulse Rate and Blood Pressure after Electro-Convulsive Therapy

\begin{tabular}{|c|c|c|c|c|c|c|c|c|c|c|c|}
\hline \multirow{3}{*}{ Nos. } & \multicolumn{2}{|c|}{ Age } & \multicolumn{4}{|c|}{ Pulse rates after convulsion } & \multicolumn{5}{|c|}{ Blood pressure } \\
\hline & \multirow{2}{*}{ Average } & \multirow{2}{*}{$\underset{\text { tremes }}{\text { Ex- }}$} & \multirow{2}{*}{$\begin{array}{c}\text { In- } \\
\text { creased }\end{array}$} & \multirow{2}{*}{$\begin{array}{c}\text { Un- } \\
\text { changed }\end{array}$} & \multirow{2}{*}{$\begin{array}{c}\text { De- } \\
\text { creased }\end{array}$} & \multirow{2}{*}{$\begin{array}{l}\text { Av. in- } \\
\text { crease per } \\
\text { minute }\end{array}$} & \multicolumn{2}{|c|}{ Average } & \multirow{2}{*}{$\begin{array}{c}\text { In- } \\
\text { creased }\end{array}$} & \multirow{2}{*}{$\begin{array}{l}\text { Insigni- } \\
\text { ficant } \\
\text { change } \dagger\end{array}$} & \multirow{2}{*}{$\begin{array}{c}\text { De- } \\
\text { creased }\end{array}$} \\
\hline & & & & & & & Before & After & & & \\
\hline $\begin{array}{c}\text { Women } \\
38\end{array}$ & $43 \cdot 3$ & $24-69$ & 34 & 3 & 1 & 23 & $150 / 91$ & $147 / 87$ & 12 & 12 & 14 \\
\hline 9 & 47 & $24-62$ & 7 & 1 & 1 & 17 & $145 / 90$ & $135 / 81$ & 1 & 4 & 4 \\
\hline $\begin{array}{c}\text { Men } \\
13\end{array}$ & $43 \cdot 6$ & $26-62$ & 12 & - & 1 & 27. & $129 / 80$ & $136 / 75$ & 4 & 6 & 3 \\
\hline 3 & 46 & $27-62$ & 3 & - & - & 32 & $145 / 83$ & $173 / 98$ & 2 & 1 & - \\
\hline
\end{tabular}

The decrease in blood pressure lay within a similar range: the greatest fall was from $185 / 100$ to $120 / 80$ and is probably, in part, a measure of anxiety.

Three patients with severe hypertension showed slight elevation of the systolic or diastolic levels or both.

None of these patients had curare before the electroplexy and it was not possible to take the blood pressure during the convulsion. As the cardiogram was taken first, there was a slight delay between the end of the fit and the recording of the blood pressure, during which it was thought that the readings might have been considerably raised. Preliminary observations of patients who have had curare and pentothal show a small initial fall and then following the convulsion there may be no considerable rise in systolic pressure, or where an increase occurs, this may be delayed for a minute or two and has not been excessive (Fig. 1). With curare in the usual dosage, there is some movement of the arms in the clonic stage, which makes a blood pressure reading usually impossible. In one patient, who had five consecutive shocks in twenty minutes, it was possible to record the blood pressure during one clonic stage (Fig. 2): the systolic level was raised $20 \mathrm{~mm}$. and remained so for 45 seconds after the convulsion had ceased. If sufficient curare is given to abolish all movement of the arms, then the likelihood of anoxia from paralysis of the respiratory muscles may make the blood pressure readings unreliable.

Hypertension was the commonest abnormal finding in routine examination, being present in 1 man and 14 women ( 29 per cent); the upper limit of normality was arbitrarily taken as $155 / 95$ at rest and on repetition. It may be suggested that these levels are too low in the circumstances, but the patients were rarely agitated or indeed alarmed at the thought of the approaching convulsion for which there is subsequent amnesia. Of these 15 hypertensives, 12 were mild to moderate and 3 were considered severe (above 220/130); one of these latter had commencing right ventricular failure. Two patients suffered from bronchial asthma of moderate degree. One patient had chronic bronchitis with early right-sided failure and one was a chronic alcoholic. In no patient was there history of cardiac pain on exertion or suggestive of a previous infarction.

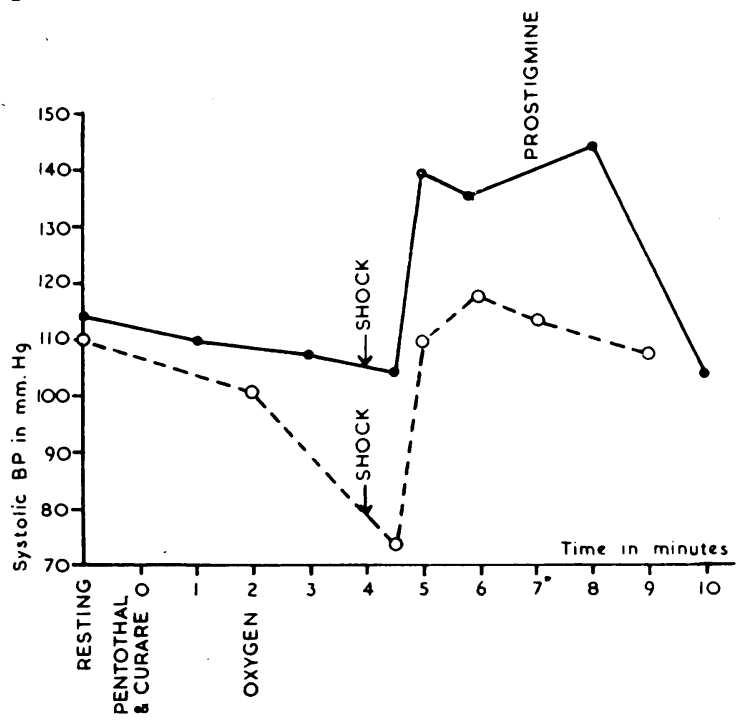

FIG. 1.-Systolic blood pressure during two convulsions under pentothal $0.5 \mathrm{~g}$. and curare $30 \mathrm{mg}$. in a man aged 45 . The second record is in dotted lines. 


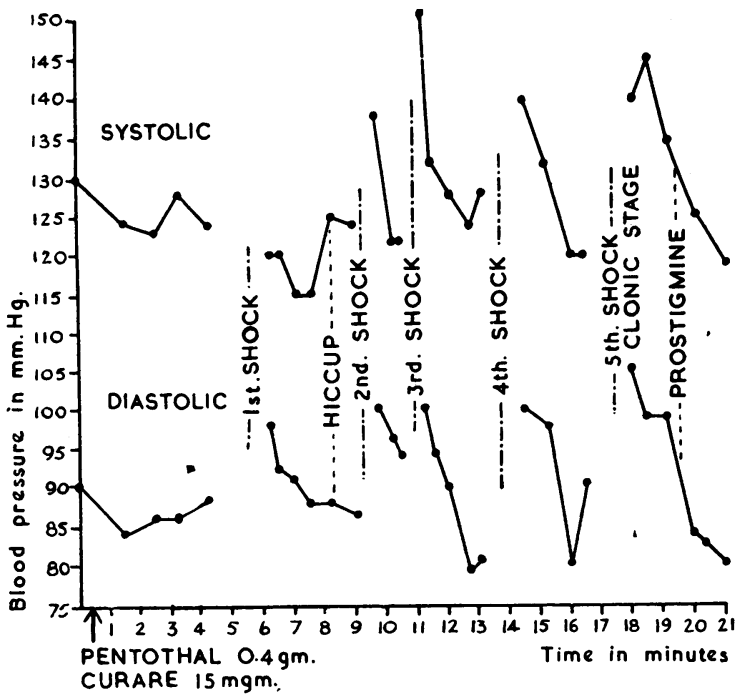

Fig. 2.-Blood pressure records in a girl aged 27 during five consecutive convulsions under pentothal $0.4 \mathrm{~g}$. and curare $15 \mathrm{mg}$.

Although the motor discharge varied considerably from patient to patient, persistently raised cervical venous pressure following the convulsion was not observed. However, Altschule, Sulzbach, and Tillotson (1947) have noted increased venous pres- sure during the convulsion and slight elevation subsequently, less evident in patients given curare.

The cardiographic changes following convulsion are summarized in Table II: the main features are increase in the height of the $P$ wave in lead II, prolongation of the $\mathrm{P}-\mathrm{R}$ interval, increase in the amplitude of the T waves in leads II and III, and less frequently diminution of $\mathrm{R} \mathrm{I}$ and depression of S-T II (see Fig. 3).

An increase in P II was present in 61 per cent of patients, the increment ranging from very slight up to $1.5 \mathrm{~mm}$.; this was reflected to a lesser extent in lead III (31 per cent). The P-R interval was lengthened in 52 per cent; this was invariably associated with an elevation of P II, although the converse was not necessarily so. No gross prolongation was found, the increase lying between 0.02 and $0.06 \mathrm{sec}$.

R I was diminished in size in 29 per cent; the most marked reduction was $-5 \mathrm{~mm}$. This diminution was not accompanied by any constant change in the complex, nor was it consistently present on repetition of the cardiogram after subsequent convulsions.

Depression of the S-T segments occurred chiefly in lead II, was slight in extent, and present in 29 per cent. Elevation of the T waves was noted in lead II in 55 per cent and in lead III in 41 per cent; the

TABLE II

Electrocardiographic Changes following Electro-Convulsive Therapy•

\begin{tabular}{|c|c|c|c|c|c|c|c|c|c|c|c|c|}
\hline Nos. & P I & P II & P III & P-R & R I & S-T II & S-T III & T I & \multicolumn{2}{|l|}{ T II } & \multicolumn{2}{|l|}{ T III } \\
\hline & + & + & + & +- & +- & - & - & +- & + & & +- & - \\
\hline $\begin{array}{l}\text { Women } \\
38\end{array}$ & 2 & $22 \mathrm{~A}$ & $10 \mathrm{~A}$ & $22 \quad 1$ & 314 & 8 & 6 & 04 & 18 & 4 & 15 & 2 \\
\hline $\begin{array}{c}\text { In subsequent } \\
\text { convulsions } \\
9\end{array}$ & 1 & 3 & 3 & 30 & $\begin{array}{ll}0 & 5\end{array}$ & 4 & 2 & 10 & 4 & 1 & 5 & 0 \\
\hline $\begin{array}{c}\text { Men } \\
13\end{array}$ & 2 & 9 & 6 & 40 & $4 \quad 1$ & 7B & 4 & $\begin{array}{ll}1 & 1 \\
\end{array}$ & 10 & 0 & 6 & 0 \\
\hline $\begin{array}{c}\text { In subsequent } \\
\text { convulsions } \\
3\end{array}$ & 0 & 3 & 0 & 11 & 20 & 0 & 0 & $\begin{array}{ll}0 & 0 \\
\end{array}$ & 1 & 1 & 1 & 1 \\
\hline $\begin{array}{l}\text { Totals } \\
\text { Percentage } \\
\text { (51 cases) } \\
\end{array}$ & $8 \%$ & $61 \%$ & $31 \%$ & $52 \% \quad 2 \%$ & $14 \% 29 \%$ & $29 \%$ & $20 \%$ & $2 \% 10 \%$ & $55 \%$ & $8 \%$ & $41 \%$ & $4 \%$ \\
\hline \multicolumn{13}{|c|}{ After standard exercise in healthy young men } \\
\hline $\begin{array}{l}\text { Percentage } \\
\text { (6 cases) }\end{array}$ & & $50 \%$ & $33 \%$ & $0 \% 33 \%$ & $-\quad 17 \%$ & $67 \%$ & - & -- & $67 \%$ & $0 \%$ & $50 \%$ & $0 \%$ \\
\hline
\end{tabular}

$\mathbf{A}=\mathbf{P}$ II and P III were decreased in one patient.

B $=$ S-T II was elevated in one patient. 


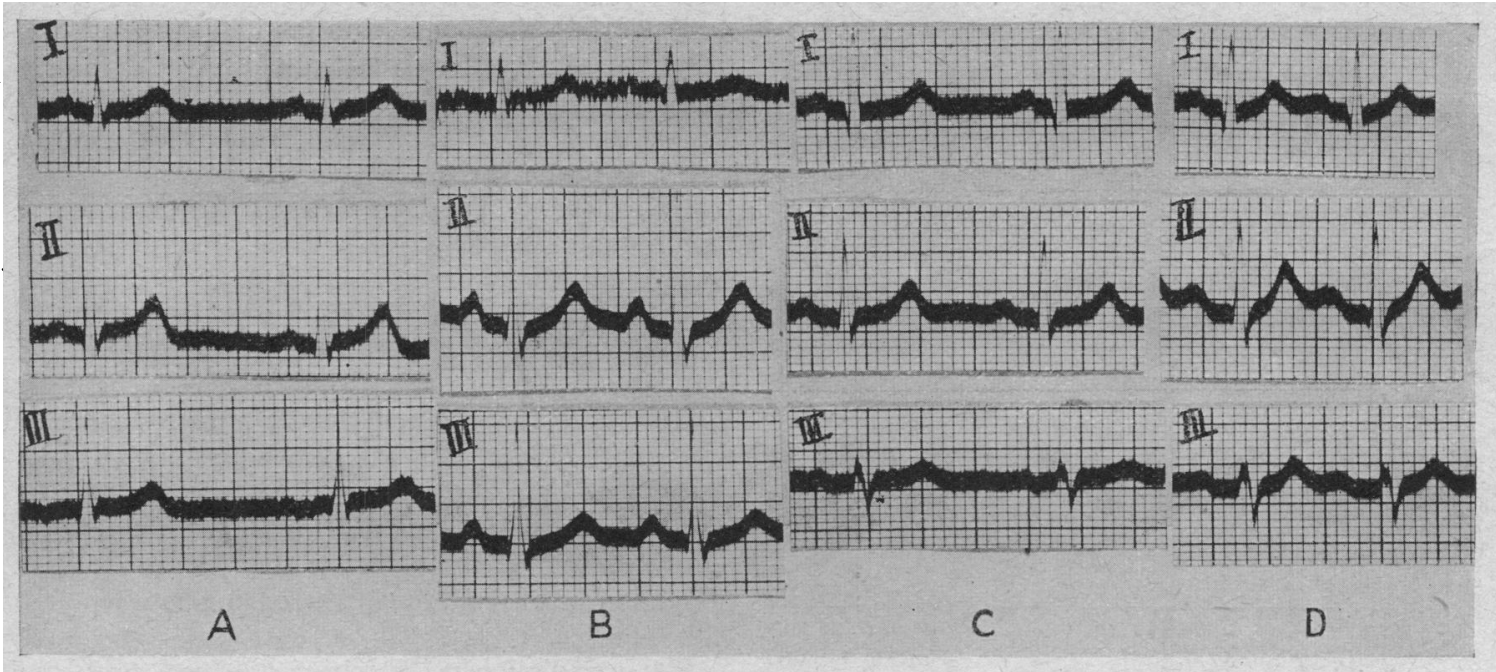

FIG. 3.-(A) before, (B) directly after the convulsion showing increase in P II and P III and slight lengthening of the P-R interval. (C) before, (D) directly after the convulsion showing increase in T II and T III.

increase in height was usually greater in lead II varying between 0.5 and $2.5 \mathrm{~mm}$.

Among less frequent changes were increased prominence of S II and S III in 5 patients, intraventricular delay in two patients unassociated with prolongation of the $\mathrm{P}-\mathrm{R}$ interval; 12 patients showed premature beats, in 4 of whom they were observed only after the convulsion, these consisted of auricular, nodal, and ventricular premature beats.

Where subsequent cardiograms were taken the pattern had reverted to the original ten minutes later.

\section{Discussion}

Increased amplitude of P II and T II and slight downward displacement of S-T II together with tachycardia are all encountered in the healthy adult following exercise (Table II), and seem best explained as the result of those processes entailed in muscular activity. As to the decrease in size of $\mathrm{R} I$, this with a trend to right axis deviation is also an accompaniment of exercise in a proportion (Wood and Wolferth, 1931), perhaps more frequent in the less fit psychiatric patients. P II elevation presumably indicates some degree of right heart strain. Some further explanation is necessary for the slight prolongation of the $\mathbf{P}-\mathbf{R}$ interval, encountered in 52 per cent, as opposed to the shortening frequently accompanying increase in the heart rate, as also for the occurrence of intra-ventricular delay. That this slowing of A-V or bundle branch conduction, in the presence of tachycardia, is due to vagal action seems most unlikely.
Two patients previously showing some lengthening of the $\mathbf{P}-\mathbf{R}$ interval following convulsion, were given atropine 1/50 of a grain before a subsequent fit and in both instances the P-R delay was again present (Fig. 4). Two further possibilities present themselves, firstly, that the lowered conductivity is caused by anoxia or secondly, is an after-effect of adrenaline. Anoxia produces increase in excursion of the $\mathbf{P}$ waves, the $\mathbf{P}-\mathbf{R}$ interval may be lengthened. the $\mathrm{S}-\mathrm{T}$ segment may be depressed and the $\mathrm{T}$ waves

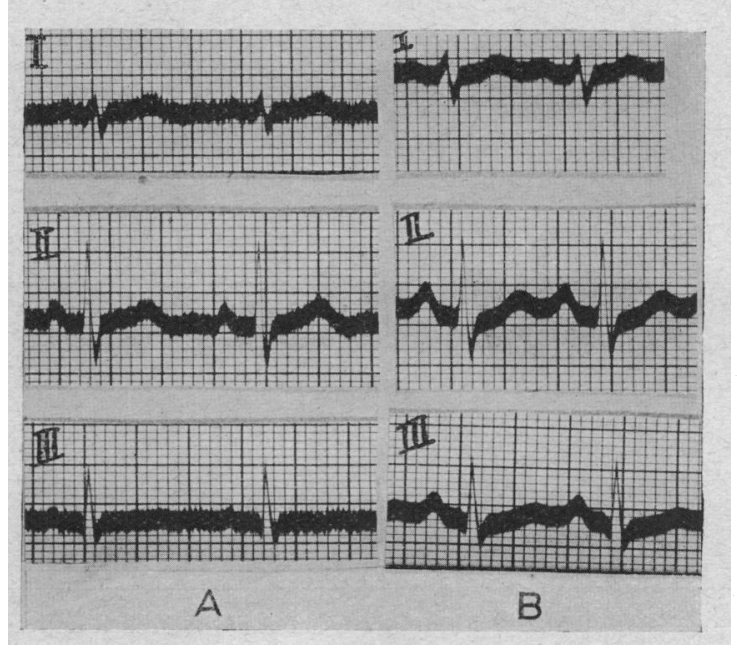

FIG. 4.-Atropine gr. 1/50, followed 20 minutes later by E.C.T. (A) before, (B) directly after the convulsion showing increase in P II and P III and slight prolongation of the P-R interval. 
lowered (Graybiel and White, 1946). Although the tonic phase of the convulsion is short and oxygen is administered from the beginning, and although cyanosis has not been remarkable, the possibility of anoxia being a factor in the production of the lowered conductivity of the bundle cannot be excluded. Alternatively, adrenaline in the experimental animal (cat) may produce partial heart block and bundle branch block after the preliminary acceleration; this, of course, in hyper-physiological concentrations. As electric shock produces a synchronous discharge such as never occurs naturally and as the passage of the current is not far removed from the prefrontal areas, it is conceivable that a very high adrenaline concentration temporarily results. Adrenaline may also be the cause of cardiac irritability, shown by ectopic beats, as occurred in a patient with a chromaffin adrenal tumour described by Espersen and Jørgensen (1947). Anoxia, however, seems the more likely factor in producing the $\mathrm{P}-\mathrm{R}$ prolongation and intraventricular delay.

Bellet, Freed, and Dyer (1939) found noteworthy cardiographic changes in two-thirds of 58 insulin shock treatments in 40 patients, namely depression of S-T segments, diminution in the height of the T waves, prolongation of the $\mathrm{Q}-\mathrm{T}$ interval and various arrhythmias including shifting pace-maker, sinoauricular block, auricular extrasystoles, and auricular fibrillation. The auricular fibrillation occurred in two patients and lasted for four and twenty-four hours respectively. Similar changes were observed by Hadorn (1937), who in addition found the P-Q interval lengthened in 10 per cent.

Nyman and Silfverskiöld (1943) stress the similarity of the electrocardiographic findings after electroplexy and those produced by the Valsalva experiment, with the exception of the markedly increased heart rate in the former. In a series of 13 patients they found increased amplitude of $P$ II (69 per cent), diminished R I in all patients and increase in T II ( 69 per cent), with return to normal after a few minutes. They postulate that the increase in intrathoracic and intra-abdominal pressure occurring in electric convulsions produces these changes.

Kolb and Vogel (1942) state that the deaths resulting from electroconvulsive therapy were 0.5 per 1000 compared with 1 per 1000 for metrazol and 6 per 1000 with insulin. Of six fatalities reviewed by Napier (1944) one was ascribed to myocardial degeneration, which was confirmed at autopsy; death occurred half an hour after the convulsion. Ebaugh, Barnacle, and Neuberger (1943) describe two deaths following electric convulsions; the first patient, aged 57 years, had anginal pain directly after the thirteenth treatment and died an hour and a half later; the autopsy revealed extensive coronary atheroma and a recent thrombosis. A previous electrocardiogram had been reported as normal. Their second patient, who had been treated with curare, died of respiratory failure. Death has also resulted from massive pulmonary œdema, two days after the second convulsion in a 35-year-old negro, who post-mortem showed meningo-vascular syphilis (Gralnick, 1945).

There was little evidence of cardiac or circulatory embarrassment resulting from electroplexy, nor was an important arrhythmia encountered in our cases, the majority of which, however, had normal or near normal hearts. None the less, in one patient with chronic bronchitis and early failure, and in the three patients with severe hypertension nothing untoward occurred. The dramatic nature of the treatment may have over-emphasized its potential dangers; although it is obviously undesirable that a patient with a history or cardiographic evidence of coronary disease should be submitted to electro-convulsive therapy, on occasion psychiatric indications may outweigh this consideration. Perhaps the risk from electroplexy, off set by curare and the particular avoidance of anoxia, is not so great as at first seemed likely. Certainly there is less danger of arrhythmia than from insulin produced convulsions. In the presence of valvular disease the possibility of precipitating auricular fibrillation exists but is probably slight.

\section{SUMMARY}

"Steepwave" electroplexy produces moderate tachycardia and little sustained change in blood pressure. With oxygen inhalation there is no obvious cyanosis. The degree of increased venous pressure during the fit is difficult to assess, but it has not been persistent clinically.

The cardiographic changes in 51 patients observed after 63 convulsions consist of elevation of P II and T II and slight increase in the P-R interval in half; R I was diminished and S-T II slightly lowered in less than a third; S II and S III were more prominent in 10 per cent; 2 patients ( 4 per cent) showed intraventricular delay; 4 patients $(8$ per cent) had heterotopic beats after the convulsion only.

It is suggested that the changes in P II, T II, R I and S-T II are the result of "muscular activity" and that the delay in auriculo-ventricular and intraventricular conductivity may be the result of anoxia.

Patients of middle age or over should have cardiograms before electroplexy is undertaken. Although evidence of coronary disease is a strong contraindication, on occasion psychiatric considerations may be so imperative as to override this. 


\section{REFERENCES}

Altschule, M. D., Sulzbach, W. M. Tillotson, K. J. (1947). Arch. Neurol. Psychiat., 58, 193.

Bellet, S., Freed, H., Dyer, W. W. (1939). Amer. J. med. Sci., 198, 533.

Ebaugh, F., Barnacle, C., Neuberger, K. (1943). Arch. Neurol. Psychiat., 49, 107.

Espersen, T., Jørgensen, J. (1947). Acta. med. Scand., 127, 494.

Gralnick, A. (1945). J. Nerv. Ment. Dis., 102, 483.

Graybiel, A. and White, P. D. (1946). Electrocardiography in Practice. Philadelphia.
Hadorn, W. (1937). Arch. Kreislauf, 2, 70.

Kolb, L., Vogel, V. H. (1942). Amer. J. Psychiat, 99, 90.

Napier, F. J. (1944). J. Ment. Sci., 90, 875.

Nyman, E., Silfverskiöld, B. P. (1943). Acta med. Scand., 114, 223.

Strauss, E. B., and MacPhail, A. (1946). Lancet, 2, 896.

Wood, F. C., Wolferth, C. C. (1931). Arch. intern. Med., 47, 339. 